\title{
El proyecto de restauración de la Puerta de Córdoba en Carmona.
}

\section{Metodologías y respuestas}



Antonio Tejedor Cabrera

Arquitecto

El Instituto Andaluz de Patrimonio Histórico inició en mayo de 1995 los primeros contactos para la restauración de la Puerta de Córdoba de Carmona, perfilando una estrategia de intervención que se apoyaba en una clara diferenciación de las etapas de conocimiento y valoración del bien inmueble, y en las aportaciones coordinadas de las diferentes disciplinas vinculadas a la conservación. Este artículo recoge la metodología seguida y los contenidos de la primera fase del Proyecto de Restauración que para el Centro de Intervención del I.A.P.H. ha elaborado el autor, profesor de Proyectos de la E.T.S. Arquitectura de Sevilla y Vocal de la Comisión Andaluza de Arqueología. 


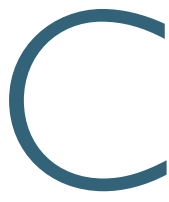

armona es un municipio situado en la Cornisa de los Alcores de la provincia de Sevilla, a unos $30 \mathrm{~km}$. de la capital. A lo largo de su historia fue núcleo de control del territorio fortalecido por la topografía natural que convirtió a la ciudad, a pesar de su ubicación en una meseta de difícil acceso, en un lugar de paso obligado en las comunicaciones del Valle del Guadalquivir. Localizada en el extremo NE del casco antiguo, la Puerta de Córdoba era una de las cuatro principales que jalonaban el recinto amurallado de la Carmo romana, precisamente por donde penetraba la Vía Augusta procedente de Corduba para salir, en el otro extremo de la población, por la Puerta de Sevilla hacia esta ciudad (Fig. I)!

Esta vaguada del escarpe del alcor enfrentada a la vega del río Corbones era, desde la antigüedad, la única puerta natural de acceso por el lado de levante al asentamiento urbano que fue extendiéndose sobre la meseta condicionado por el sinuoso contorno de ésta ${ }^{2}$. La construcción de la puerta romana como arco triunfal en el siglo I d.C. supuso en la práctica la conformación arquitectónica del acceso con un marcado carácter propagandístico en un enclave estratégico de la Bética romanizada. Diversas vicisitudes históricas fueron dando lugar a continuas remodelaciones y reconstrucciones musulmanas y cristianas hasta que el arquitecto carmonense José Echamorro le confiere su aspecto neoclásico actual entre 1796 y 1800.

Como puerta urbana que siempre sirvió para el acceso a la población por su vertiente oriental, ha tenido un "uso" continuado a lo largo de la historia, lo que unido a su privilegiada ubicación dominando el paisaje circundante justifican el extraordinario valor simbólico y cultural de este monumento civil. Flanqueada por dos bordes de alcor -el Cortinal Gil de Palma al sur y el Alcázar de la Reina al norte- la Puerta de Córdoba se percibe al atardecer, viniendo de Écija, como acueducto o puente de un solo vano que se funde con el escarpe, o como muro de contención perforado por un haz luminoso33.

\section{EL PROYECTO COMO MÉTODO}

Desde un punto de vista teórico, es evidente que la PUERTA DE CÓRDOBA es un monumento que se conserva virtualmente completo en su actual configuración, sin lagunas formales o semánticas importantes. Descartada la recuperación de estados originales de la puerta romana que ya no son compatibles con el contexto urbano actual, la intervención sobre el edificio no plantea incógnitas relevantes que exijan decisiones proyectuales complejas. Más bien se trata de asegurar la integridad material del monumento, necesaria para mantener y potenciar su valor simbólico primordial.

El proyecto puede considerarse así un simple instrumento destinado a hacer más palpables las cualidades arquitectónicas del monumento y, especialmente, los valores históricos que alberga, bien documentados en
Fig.1. Topografía del asentamiento de Carmona y sus murallas. (Antonio Jiménez Martín)
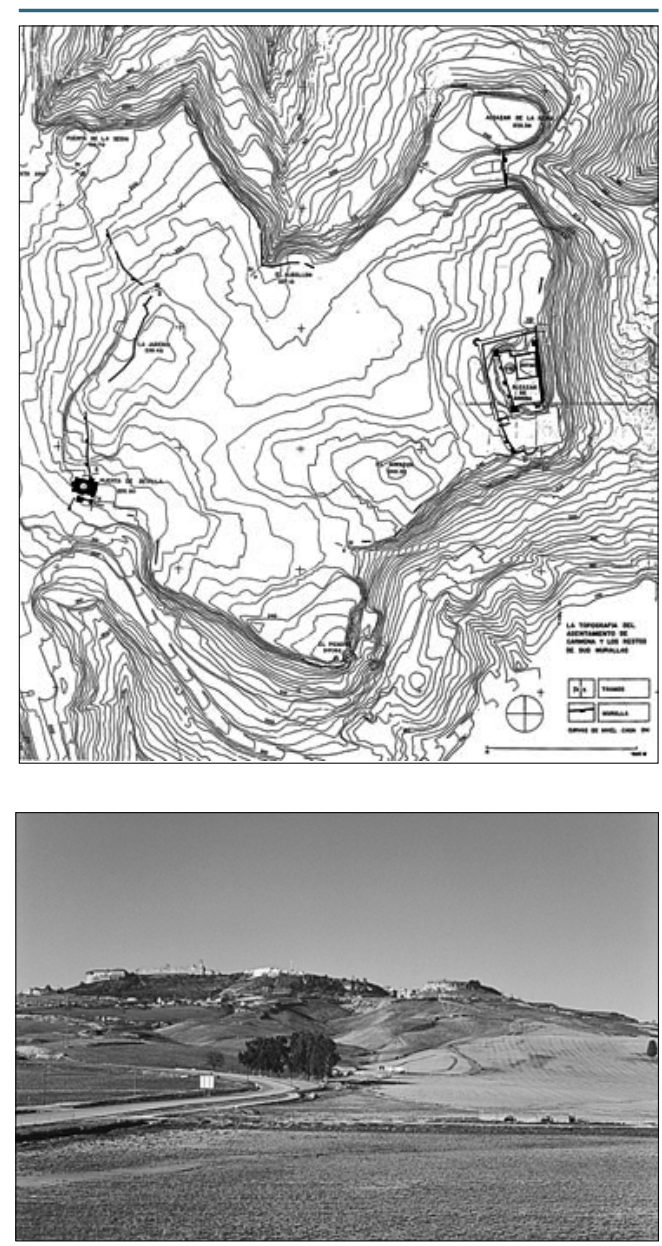

Foto 2. Vista desde la carretera N-IV.

la dirección adecuada gracias a la investigación arqueológica realizada -que tendrá su continuidad en la ejecución de la obra. Se puede afirmar incluso que la verdadera "restauración" no estriba en la intervención material que el documento de proyecto pretende perfilar, sino en la oportunidad histórica que ha propiciado el proyecto arquitectónico para el mejor conocimiento y difusión de sus valores.

Por tanto, este proyecto debe entenderse fundamentalmente como de conservación, es decir, centrado en resolver los aspectos técnicos y científicos que ello implica (limpieza, consolidación estructural, recuperación de pátinas y revocos, etc.). Entre las medidas de conservación destacan, por su especificidad, el tratamiento sobre los materiales pétreos y, por su dificultad, la eliminación de las humedades de infiltración provocadas por la singular yuxtaposición del edificio con los rellenos que históricamente se han consolidado en el lado occidental y por el adosamiento de las viviendas contiguas.

Sin embargo, estas consideraciones se enmarcan dentro de una estrategia más amplia. Las primeras iniciativas tomadas por el I.A.P.H. estaban dirigidas a perfilar una propuesta de intervención integral en tres fases y definir una metodología de trabajo para elaborar los estudios previos destinados a conocer el estado general del monumento, aportar los datos históricos, documentales y materiales necesarios y establecer el alcance de la pri- $\varangle$ س 
mera fase de intervención en la Puerta de Córdoba. El necesario enfoque interdisciplinar se extiende, por tanto, a todas las áreas de conocimiento e intervención sobre el bien y su entorno: su perfil biográfico, histórico y arqueológico; la noción constructiva y material de sus fábricas; el valor cultural, que es artístico y de identidad colectiva; las nuevas exigencias funcionales según las posibilidades de musealización del monumento y, por último, el valor paisajístico, análisis de su vínculo con el lugar y posible recuperación del entorno.

Las tres fases operativas son las siguientes:

I. La restauración del monumento (concluye con la ejecución de la obra proyectada y la $2^{\text {a }}$ campaña de investigación arqueológica).

2. La puesta en valor y musealización (nuevo uso). Esta fase de intervención está fundamentalmente destinada a incorporar los restos del podio romano excavado en la campaña arqueológica y facilitar el acceso al ático dentro de una visita selectiva del monumento, con la posibilidad de convertir la Puerta de Córdoba en un centro de interpretación territorial de Carmona, que complete la oferta patrimonial y turística de la ciudad ${ }^{4}$.

3. Tratamiento del entorno. La visión integral de recuperación de la Puerta de Córdoba que pretendemos desarrollar abarca especialmente al entorno inmediato y distante. La modificación puntual de las obras de pavimentación desarrollas en los últimos años en la explanada delantera y la eliminación del vertedero que se generó en la vaguada contigua segando la visión lejana de la puerta son objetivos principales a medio plazo de esta última fase. Esta intervención incorporará además la puesta en valor de la dimensión paisajística y escénica de la Puerta de Córdoba, contemplando actuaciones de distinta intensidad como: nuevas plantaciones de arbolado, nueva iluminación monumental, y restauración de otros elementos relevantes del entorno como son los restos de la calzada romana (Vía Augusta) y el puente de los cinco vanos, que están declarados B.I.C. en la actualidad. La eliminación de los asentamientos y cobertizos que jalonan la carretera de acceso junto el alcor sur es también uno de los objetivos que el Ayuntamiento debe incorporar al proceso de revalorización paisajística de la Puerta de Córdoba.

Por lo que respecta a la primera fase, la metodología general seguida en la elaboración del proyecto puede esquematizarse en los siguientes pasos, a menudo simultáneos en el tiempo:

I. Investigación de la biografía de la Puerta, relativa a su origen, construcción y ruina, trabajos de refacción, obras de conservación, mantenimiento y reparación, etc. Se articula mediante la investigación documental y la investigación con metodología arqueológica tanto de las estructuras subyacentes como de los paramentos emergentes.

2. Levantamiento planimétrico: reportaje fotográfico exhaustivo y apoyo taquimétrico (con 17 estaciones y 250 puntos). Inventario de las lápidas y del material existente en el ático de la propia Puerta.

3. Inspección ocular detallada del edificio, observando el estado de conservación de los materiales mediante el análisis de los indicadores visuales de alteración (según nuestra libre interpretación de la clasificación de los profesores Antonio Martín y Manuel Alcalde 5 ) y su documentación mediante fotografías y croquis detallados.

4. Determinación de las características mineralógicaspetrográficas de la roca original y alterada y localización de las posibles canteras.

5. Ensayos químicos para determinar los componentes de la roca original y la roca alterada.

6. Ensayos sobre características fisico-mecánicas de la roca original y la roca alterada.

7. Caracterización de morteros y microestratigrafía de los enlucidos.

8. Selección de los productos de consolidación e hidrofugación de la piedra mediante ensayos de envejecimiento artificial acelerado sobre probetas de piedra tratada.

9. Investigación geotécnica: características del suelo, resistencia y profundidad del nivel freático.

10. Propuesta de intervención y redacción del documento de proyecto. Realización de una maqueta de madera de la puerta y su entorno.

Se ha prescindido por el momento de los siguientes estudios: conocimiento de los factores ambientales mediante el análisis climático del entorno próximo, (basado en la obtención y recogida de datos muestrales de temperatura y humedad relativa), análisis biológico y estudio de cromías originales.

\section{EL MONUMENTO COMO ARQUITECTURA}

La Puerta de Córdoba puede describirse como un arco de medio punto flanqueado por dos torreones semioctogonales que enlazan con los dos macizos de alcor mediante sendos lienzos de muralla. Estos lienzos laterales en contacto con el alcor son muros rectos de sillería atizonada, de unos diez metros de altura en la actualidad y casi tres metros de espesor ${ }^{6}$. Dos torres de flanqueo enmarcan la Puerta propiamente dicha con su actual fachada escenográfica que perdió en gran parte su aspecto militar a finales del siglo XVIII para dotarse de su imagen actual cuando el interés que poseía ya no era defensivo sino que estaba dado por la topografía y por su misión "estratégicamente" simbólica de acceso a la ciudad (fig. 2).

Las torres semioctogonales, de 3,40 m. de lado y II, 10 $m$. de altura, se nos muestran hoy día con distinta apariencia según el grado de conservación de la cuidadosa obra 


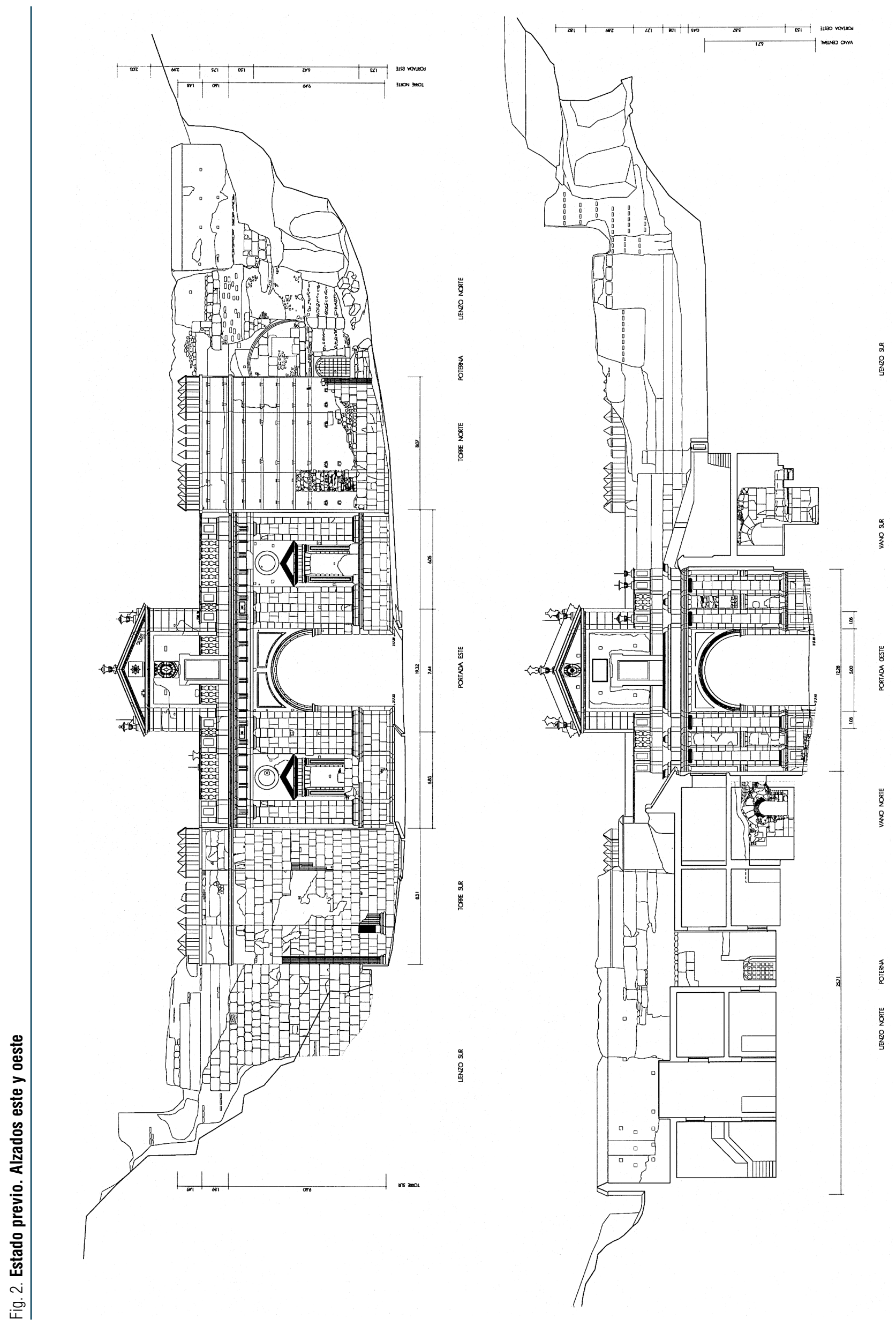




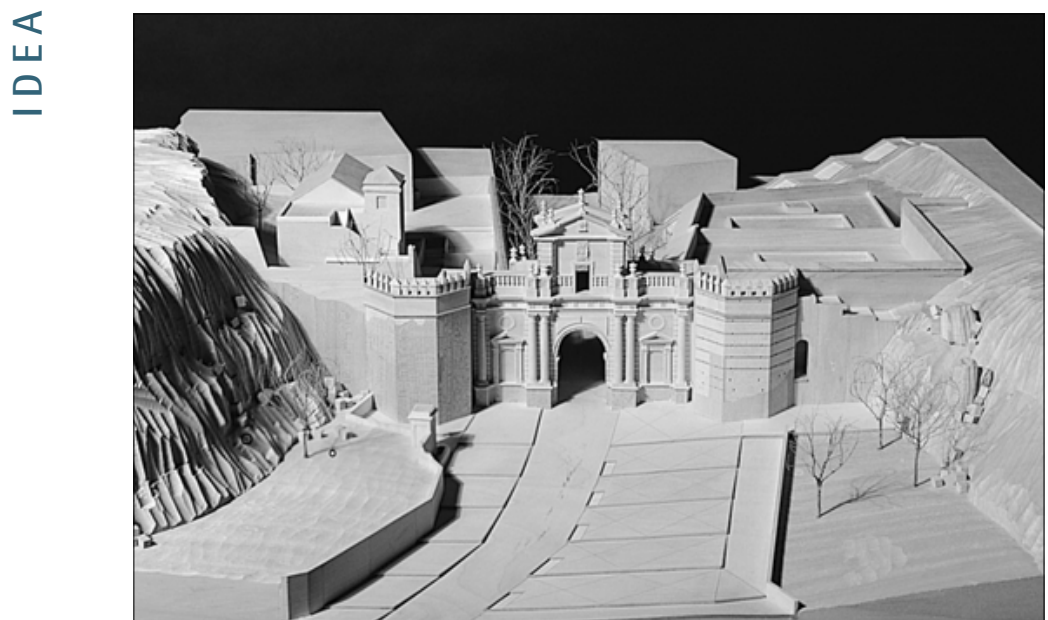

Foto 3. Maqueta de sillería en la que destaca la labra decorativa bastante mutilada en los ángulos, mejor conservada en la torre sur. Cada esquina visible de los torreones estaba decorada con dos pilastras en relieve formadas por basa ática sin plinto sobre un doble zócalo, fuste con estrías y contraestrías en el imoscapo. La mejor conservada alcanza ahora 6,30 m. de altura en el lado sur de la Torre meridional. En origen estarían decoradas con capiteles sobre los que se desarrollaría el entablamento del primer cuerpo. Los remates actuales son de fábrica mixta de mampostería y tapial coronada por dos listeles de ladrillo y merlones de ladrillo terminados en punta de diamante, que están documentados con anterioridad a la guerra civil7.

El paramento entre torreones tiene la altura aproximada de éstos sin las almenas: la línea de cornisa coincide con el listel más bajo de los dos mencionados. Se trata de una composición neoclásica de columnas toscanas pareadas, que se remata con falsa balaustrada y ático coronado por un frontón con jarrones-acróteras sobre la bóveda del vano central. ${ }^{8} \mathrm{La}$ altura total en el eje vertical alcanza los 17m. En la decoración de esta fachada, cuyos podios son de sillería superpuesta a la romana (que puede observarse que permanece en segundo plano a través de algunas pérdidas de la piel neoclásica) destacan dos ventanas y óculos fingidos que centran los intercolumnios, pilastras almohadilladas remarcando las columnas y friso decorado con triglifos y metopas. Dos escudos de mármol del s. XVIl, uno real y otro de la ciudad, rematan la decoración?.

El arco de acceso, único en la actualidad, es una bóveda de cañón de 6 m. de longitud; en este vano se localizan, del exterior al interior de la ciudad: la ranura del rastrillo original de la puerta romana, una hornacina que alberga un lienzo del siglo XVIII de la Virgen de Gracia, y en el lado derecho, una lápida circular con epigrafía en el que se indica que bajo el reinado de Carlos II, entre 1688 y 169I, el maestro Alonso Rodríguez "hizo la fábrica de esta calzada real sea con honra y gloria de la reina de los ángeles María de Gracia" transcrito del castellano antiguo original.

La fachada de la Puerta que da a la ciudad es similar a la exterior pero de pilares jónicos y cornisa denticulada, de composición más sencilla y de 12,30 m. de desarrollo y 15,80 m. de altura hasta el vértice del frontón. Algunas molduras del arquitrabe enlazan con el muro de la casa contigua por el lado sur de la calle Dolores Quintanilla, haciendo evidente su coetaneidad. En el ático de esta fachada intramuros existen dos lápidas ${ }^{10}$. Desde la casa antes citada se accede al ático por medio de una escalerarampa adosada al adarve y la torre sur.

Importante es destacar la sillería del pasadizo del lado sur, al que se accede a nivel de la calle, por el rincón del patiozaguán de llegada a la casa. Se trata de una bóveda de cañón de I,70 m. de luz y 5,70 m. de profundidad. A la izquierda "se abre un hueco de paso a la que fue la primera vuelta de una escalera, como denuncia su bóveda rampante, que gira a derechas en dos ocasiones. La labor de estereotomía es extraordinaria especialmente en los encuentros de las bóvedas rampantes. Se ilumina mediante una saetera esviada que aparece bastante disimulada en la fachada exterior tras una de las columnas de la composición principal en el lado meridional de la Puerta". Del lado septentrional de la Puerta debió existir una escalera similar, extremo que se comprobará en obra, conservándose un pasadizo similar al anteriormente dicho que atravesaba la Puerta, conformándola en época romana como puerta de tres vanos.

En el entorno inmediato destacan las casas $n^{\circ} 47$ y $n^{\circ} 36$ de la calle Dolores Quintanilla (en adelante casas sur y norte, respectivamente) que han sido levantadas a fin de obtener una compresión más precisa del "encastramiento" de estas edificaciones sobre la fábrica romana y medieval (fig 3 y 4 ).

\section{Análisis funcional}

La Puerta es un edificio de extraordinarios valores estéticos e históricos pero no puede quedar como simple pieza urbana objeto de veneración. El conocimiento pormenorizado de las funciones realizadas en el pasado por la Puerta de Córdoba y su permanencia o transformación en el tiempo nos puede marcar el sentido de la "puesta en valor" que queremos acometer como conclusión de la actuación integral en la propia puerta y en su entorno. De todas esas funciones algunas han desaparecido y otras se han reducido considerablemente por pura ineficacia:

- Acceso principal a la población, inherente al origen de la construcción y asociada a su carácter militar original. La tipología de puerta de tres vanos, los dos laterales de paso peatonal desaparecidos ya en el Bajo Imperio, no es recuperada con la superposición de la piel neoclásica, debido a que las transformaciones urbanas habrían reducido el ancho de la calle con anterioridad, impidiendo en la práctica la circulación por los vanos laterales. El acceso a la ciudad llevaba asociado actividades de diversa índole como son las de aduana y control de mercancías. El abrevadero representa así un papel fundamental en la comprensión de esta función primera de la puerta.

- Misión defensiva: su ubicación topográfica y sus características constructivas le confieren una posición privilegiada como atalaya militar, e incluso almenara 

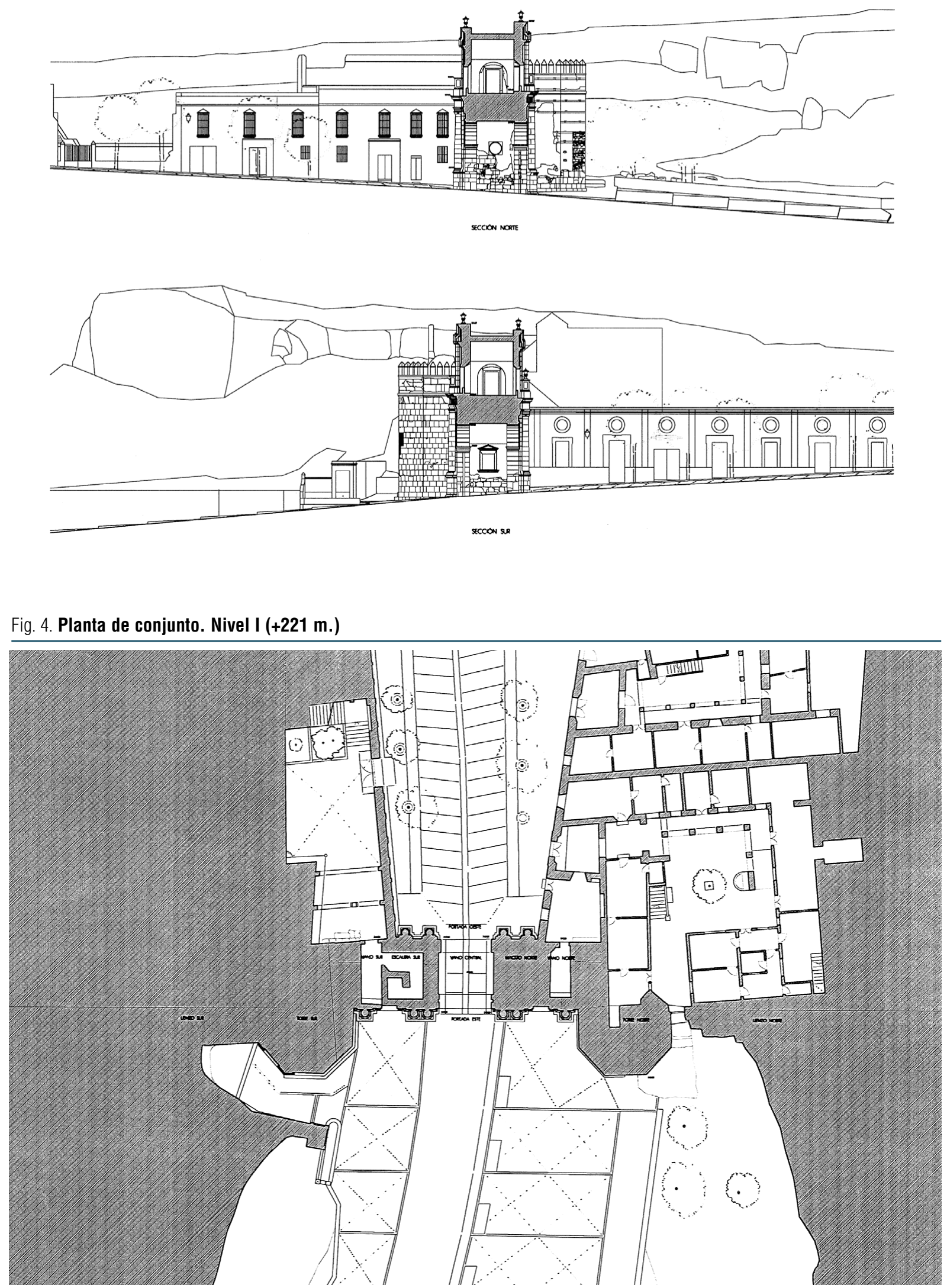
o torre de avisos. Esta función ha sido sustituida por la de simple mirador para el visitante afortunado que puede acceder a su parte alta.

- Depósito de materiales en la actualidad y en el pasado reciente. El ático ha sido utilizado también como establo y como capilla ocasional, según el testimonio del encargado de la casa contigua por el lado sur.

- Desde un punto de vista religioso: inspiración, auxilio y aliento espiritual al que la traspasa. La ubicación de un cuadro de la patrona de Carmona, la Virgen de Nuestra Señora de Gracia, contiene valores de carácter etnológico muy difundidos en nuestro entorno cultural.

- Señalando acontecimientos políticos y militares, honores, refacciones de la propia fábrica, o siendo el soporte del lema de la ciudad, refuerza su carácter simbólico y representativo de la identidad local.

- Por sí misma la Puerta de Córdoba constituye uno de los elementos significativos de la visión más sugerente de Carmona por sus implicaciones paisajísticas y monumentales. Desde su construcción tuvo un marcado carácter simbólico y propagandístico que se refuerza a partir del siglo XVII y nuevamente a finales del siglo XVIII.

\section{EL MONUMENTO COMO DOCUMENTO}

\section{La investigación histórica, documental y bibliográfica}

Los estudios histórico-artísticos de la Puerta de Córdoba fueron iniciados por D. Alfonso Jiménez Martín quien elaboró un informe que sirvió de base para el desarrollo de los trabajos previos posteriores gracias a la variedad de información que contenía. Su alcance estaba fijado en el prólogo del documento presentado:

"I Descripción literaria de la Puerta de Córdoba en Carmona y su contexto, con examen detenido de las vicisitudes históricas y aportación de los textos bibliográficos concernientes, deteniéndonos en la valoración que el edificio ha merecido a los historiadores...

2 Recopilación selectiva y analítica de la documentación gráfica que hemos podido allegar, con especial insistencia en los alzados esquemáticos de su apariencia anterior a las decisivas obras de la última década del siglo XVIII.

3 Levantamiento del edificio según la apariencia que, en nuestra opinión, tendría en el momento de su inauguración a comienzos del siglo XIX; para ello hemos partido de la integración de tres fuentes gráficas de carácter muy distinto, como es, en primer lugar, un levantamiento tradicional de las partes interiores, es decir, mediante croquizado y medida por medios artesanales, en segundo lugar un levantamiento minucioso por medio de estación total de todos los elementos fundamentales de la apariencia tridimensional del objeto y, finalmente, prelevantamiento fotogramétrico con una cámara calibrada, tarea que ha realizado D. Antonio Almagro Gorbea".

A modo de resumen destacaremos del estudio del profesor Jiménez los siguientes aspectos:

- El extraordinario valor topográfico, que entendemos como territorial y paisajístico, del enclave de la Puerta de Córdoba, que es clave en la comprensión de su relevancia histórica y defensiva.

- Estamos ante la "única puerta de Hispania con alzado, donde percibimos las preocupaciones compositivas que eran normales en Italia en los comienzos del Imperio romano, cuando los pasos de las murallas se vistieron con ropajes de fachadas palatinas". Parecidos formales con uno o tres vanos existen en: Spello (Puerta de Venus); Fano (Arco de Augusto); Nimes (Puerta de Augusto); Autun; Turín; Arles; Frejus; Vindonissa.

- Son fechas significativas de intervenciones:

- 478. Destrucción del inmediato Alcázar de la Reina

-1608. Reconstrucción y decoración con estatuas de mármol

- |688. Obras en la calzada. Rango de ciudad para Carmona con Carlos II

-1766, Plantación de una alameda en la Puerta de Córdoba

-1774-75. Dibujos de la Puerta totalmente almenada

-1796-1800. Obras de reforma del arquitecto José Echamorro

-194I y 1965. Obras de Félix Hernández, simultáneas a las de la Puerta de Sevilla.

-1989. Obra de emergencia, Delegación Provincial de Culturall.

Para terminar este apartado, señalar que esta fase de investigación no ha concluido. Al contrario, es uno de los objetivos prioritarios de la intervención extender su alcance durante la realización de la obra y en paralelo con los trabajos de seguimiento arqueológico que se contemplan en este proyecto. La investigación se completará con el estudio paisajístico del entorno, evolución de las ocupaciones de las laderas de los alcores, modificaciones de tipo urbanístico, pavimentaciones, transformaciones funcionales, condiciones ambientales, etc.

\section{La investigación arqueológica}

Junto a la investigación analítica de materiales pétreos y revestimientos es, sin duda, la investigación con metodología arqueológica que han realizado Reyes Ojeda y Miguel Ángel Tabales, la que ha reportado mayores datos para el conocimiento previo del monumento, sus vicisitudes históricas y sus potencialidades de pues- 
ta en valor, al sacar a la luz restos que muestran la relevancia de la puerta romana.

Nos interesa destacar especialmente las aportaciones que la arqueología nos hace sobre las características materiales del edificio y la clasificación de sus paramentos por etapas históricas, dada la utilidad que tienen para calibrar adecuadamente el nivel de intervención óptimo en función del valor histórico-documental de algunas partes en relación con otras más recientes $^{12}$. Resumidamente recogemos algunas de las aportaciones de la investigación arqueológica realizada:

- Se ha puesto de manifiesto la estructura muraria de la Puerta, fechable en el siglo I DC (época Flavia) consistente en un acceso de triple vano, con dos torres de flanqueo. Los accesos laterales, de menor tamaño, cegados ya en el Bajo Imperio, han permanecido ocultos por las dos casas adosadas a ambos lados de la Puerta que los han incorporado como estancias de almacenaje. Respecto a la puerta romana, se conserva gran parte del alzado correspondiente al primer cuerpo, "forrado" por la fachada neoclásica, y las escaleras abovedadas de subida a la $2^{\text {a }}$. planta.

- El estado de conservación, el significado propagandístico con que fue concebida su ubicación y composición original y la amplitud de la fachada interior, que sobrepasa los $30 \mathrm{~m}$. de longitud, convierten a la Puerta de Córdoba en la puerta romana más monumental de las documentadas en Andalucía y en una de las pocas que aún conservan su función primigenia.

- El análisis estratigráfico aplicado a la lectura de alzados ha permitido datar los paramentos según seis etapas históricas: siglo I d.C.; bajo romano-alto medieval; bajomedieval-final siglo XIII-s. XV; s, XVI-s. XVII; I796-I800; final s. XX. También se ha realizado un análisis tipológico-estructural que contempla los distintos tipos de adosamiento de las fábricas y una clasificación de los aparejos de ladrillo, piedra, tapial y mixtos, resultando diez tipos diferentes. ${ }^{13}$

La campaña de excavaciones y análisis paramental se completó con un "estudio tafonómico y paleobiológico del registro óseo de la Puerta de Córdoba".14

\section{El levantamiento planimétrico}

La planimetría básica del monumento fue aportada por el profesor Alfonso Jiménez, quien señala en su informe sobre la Puerta de Córdoba que los planos "han sido realizados en el primer trimestre del presente año (1995) ya que el material antiguo no nos resultó fiable". Para este levantamiento recurre a un prelevantamiento fotogramétrico con cámara calibrada, aunque no aporta la "minuta" fotogramétrica en su informe, de lo que deducimos que sólo se realizaron los fotografías y el apoyo con taquímetro digital. Esta planimetría no incorporaba los lienzos laterales ni el adosamiento de las viviendas contiguas al monumento.
A falta de un levantamiento fotogramétrico de los dos alzados realizamos un completo apoyo taquimétrico con 17 estaciones para el levantamiento de 250 puntos significativos del monumento. Los resultados del trabajo de campo fueron trasladados a un programa informático de dibujo asistido que permitía recoger la información tridimensional. Se buscaba, especialmente, la definición precisa de los planos de proyección de los alzados y el apoyo exhaustivo de los lienzos laterales de la puerta que nunca habían sido levantados con anterioridad, tanto por el lado de levante como por el poniente, es decir, representando el contacto del monumento con el alcor y con las estructuras edilicias adosadas a él. Este trabajo nos permitió, además, comprobar la geometría y simetría de la composición neoclásica y facilitó la toma de datos in situ con métodos manuales tradicionales de cinta métrica, lápiz y papel que completaban la información obtenida con el taquímetro ${ }^{15}$.

A partir del dibujo tridimensional, de los croquis acotados in situ y de un extenso reportaje fotográfico, se completó el levantamiento en ordenador con las proyecciones siguientes:

I. Planta Nivel I. Puerta de Córdoba. E: I/50.

2. Planta Nivel 2. Ático. E: I/50.

3. Planta Nivel 3. Cubiertas. E: I/50.

4. Planta general Nivel I. Entorno. E: I/I00 (fig. 4).

5. Planta general Nivel 2. Entorno. E: I/I00 (fig.5).

6. Alzado Oeste. E: I/50

\section{Alzado Este. E: I/50.}

8. Sección transversal hacia el Sur. E: I/50.

9. Sección transversal hacia el Norte. E: I/50.

También se procedió a "escanerizar" el plano topográfico de la zona a escala 1/500, del Centro de Estudios Territoriales y Urbanos de la Consejería de Obras Públicas y Transportes. Junta de Andalucía. Nº de hojas: 985/54-12 y 53-12. A partir de este plano se confeccionó el plano de situación y se comprobó la concordancia dimensional del monumento y su entorno, ya levantado, con la planta del mismo tal y como aparece grafiada en el topográfico mencionado.

El levantamiento planimétrico ha sido, sin duda, el trabajo más dilatado en el tiempo, con un detenido proceso de ajuste de los planos que las estudios previos iban generando. Resolver las contradicciones, errores y olvidos de los planos elaborados con anterioridad, y completar el levantamiento del monumento con la incorporación del entorno inmediato, son labores muy importantes para la intervención arquitectónica -que se inicia de hecho con la elección de los criterios de representación y las proyecciones óptimas para la presentación global del monumento- sobre las que queremos insistir de cara a una mayor coherencia en la coordinación de estas tareas, capaz de evitar la repetición de trabajos que bien realizados desde un principio no resultan tan fatigosos ni costosos. 
Fig. 5. Planta de conjunto. Nivel II (+229 m.)

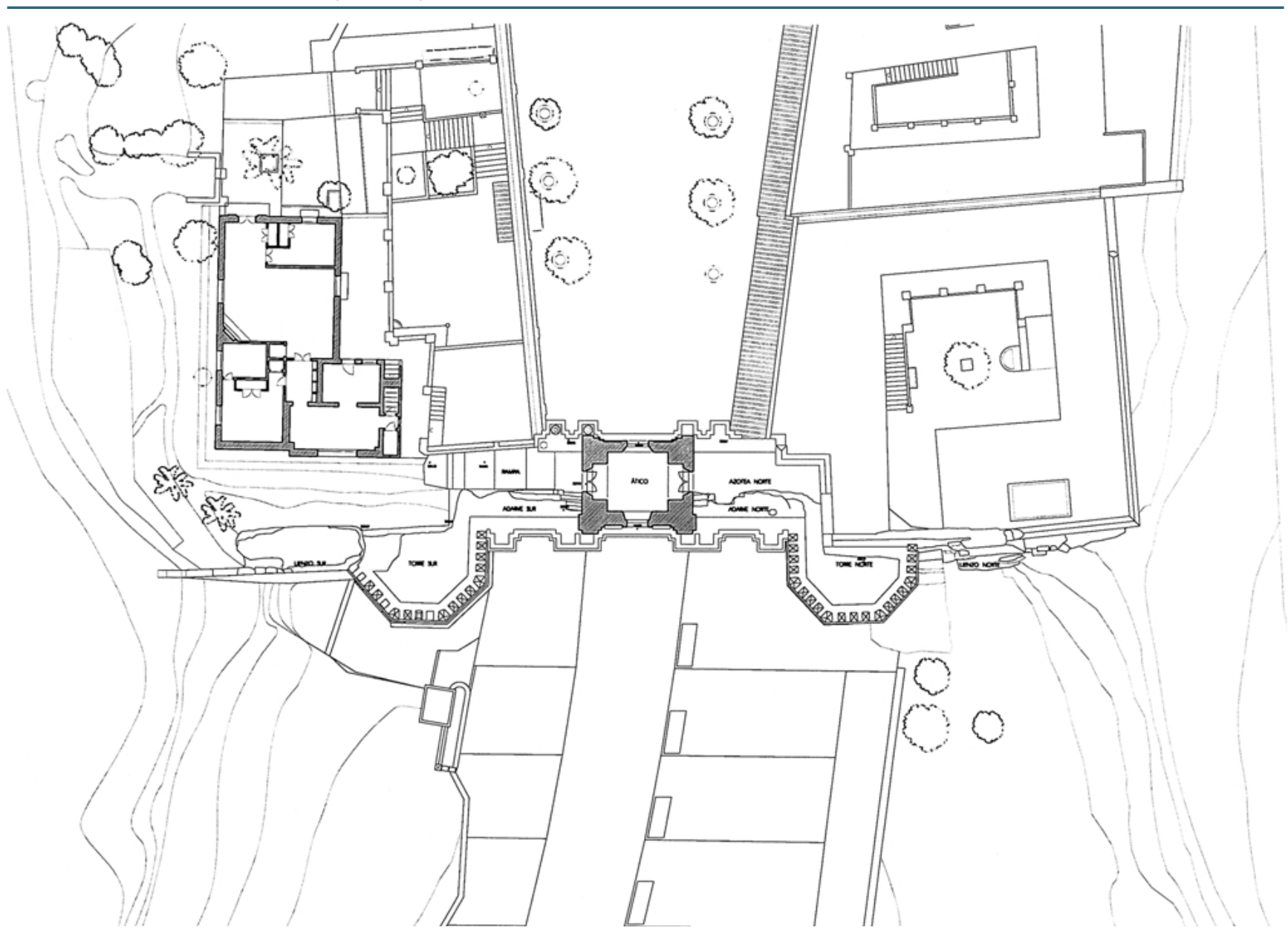

La investigación de los materiales y el suelo

\section{ANÁLISIS Y ENSAYOS DE MATERIALES Y TRATAMIENTOS}

El análisis de los materiales empleados en la Puerta de Córdoba y la evaluación de tratamientos para la piedra han sido realizados por el Departamento de Análisis del Centro de Intervenciones del I.A.P.H. Los análisis han estado dirigidos, por un lado, a la caracterización de los materiales pétreos, a través de sus características químicas, físico-mecánicas, mineralógico-petrográficas, de compacidad y de comportamiento del material frente al agua. Por otro lado, se ha realizado la caracterización de los morteros y enlucidos. También se han efectuado experiencias de alteración acelerada, sobre probetas de piedra extraídas del monumento, con el fin de comprobar su comportamiento después de ser tratadas con cuatro productos comercializados para la consolidación e hidrofugación ${ }^{16}$. Resta por hacer una caracterización de ladrillos y una cromatografía de revestimientos, que podría acometer el I.A.P.H. durante los primeros meses de la obra.

Entre las conclusiones de estos estudios destacaremos las siguientes:
- La piedra utilizada en la Puerta de Córdoba procede de la formación geológica de los Alcores, una calcarenita de color amarillo-anaranjado, con tamaño de grano de arena gruesa y presencia de lamelibranquios de concha fina. La composición mineralógica de la piedra de la puerta es similar a la de las distintas canteras estudiadas 17 , destacando la presencia de yeso como un componente intrínseco al material (aunque una parte pueda proceder de los morteros de unión) y una escasa proporción de minerales de arcilla (ilita y especialmente esmectitas que son arcillas expansivas). Estos componentes, además de la gran porosidad de la piedra -en torno al 34\%-, explicarían el alto grado de alteración de la piedra en los paramentos sometidos a cambios cíclicos en el contenido de humedad.

- En los morteros utilizados en la obra neoclásica, destaca la presencia de sulfatos (yeso). En los enlucidos exteriores la inexistencia de fragmentos de roca carbonatada indica una mayor selección en el árido.

- En base a los resultados obtenidos en la medición de la disminución de porosidad, incremento de dureza superficial, absorción por capilaridad, absorción libre de agua, desorción de sales, cristalización de sales y evolución del peso con ciclos de humedad-sequedad, los productos de consolida- 
ción e hidrofugación más adecuados para la piedra son, respectivamente, Consolidante $\mathrm{OH}$ y Tegosivin $\mathrm{HLI} 00 \mathrm{I} 8$.

\section{INVESTIGACIÓN GEOTÉCNICA}

Se ha realizado un estudio geotécnico por la empresa AICIA-IUCC bajo la dirección del profesor José Luis de Justo Alpañés realizándose los ensayos en el laboratorio de la Escuela Técnica Superior de Arquitectura de Sevilla. A partir de dos sondeos rotatorios realizados, uno en el estribo sur de la puerta y otro en el ángulo que forman la fachada oriental y el torreón norte, se han elaborado los cortes de suelo y los ensayos de identificación (límites de Atterberg y granulométricos) y de compresión simple.

Este estudio complementó el análisis de las características materiales y dimensionales de la cimentación que se habían determinado por medio de una cata arqueológica hasta la base de la cimentación. En esta cota, el suelo es de transición a marga con una alta resistencia a compresión simple (entre 2,5 y 3,25 kp/cm²).

\section{ESTADO ACTUAL, ALTERACIONES Y PATOLOGÍAS}

Como marco general del estudio de patologías se ha partido del análisis de las características constructivas del monumento y de las siguientes consideraciones:

Estructuralmente la Puerta de Córdoba no presenta patologías de gravedad que pongan en riesgo su integridad, excepto en el lienzo norte. Las grietas observadas en el vano central junto al arco oriental pueden tener su origen tanto en una escasa trabazón de los paños de fachada respecto del relleno de la bóveda y de los paños de fachada del ático respecto de sus muros laterales de cerramiento, como en las vibraciones producidas por el paso de vehículos a través del vano central. Otras problemas de carácter estructural se producen en los adarves de los lienzos norte y sur, ambos relacionados con la pérdida de masa y socava del alcor, mucho más graves en el lienzo norte por pérdida de la cortina muraria de sillares (opus quadratum) que ha dejado al descubierto el emplekton romano y en precaria estabilidad los recrecidos de tapial que se superponen. Desconocemos el momento en que se dispone el arco de descarga de traza apuntada y el relleno ataluzado que se le acompaña aunque nos hablan de problemas de estabilidad parcial desde muy antiguo que no quedaron resueltos, dadas las grietas y pérdidas que presentan. Todo ello se agrava, aun más, por la erosión del alcor en las proximidades del lienzo, tal y como ocurre en el otro extremo de la puerta, lo que en la práctica se traduce en una pérdida recíproca de sustentación.

La disposición de la Puerta de Córdoba entre dos alcores y recogiendo, como si se tratase de un muro de contención, los desniveles del alcor y los rellenos entre el interior y el exterior, suponen la transmisión de
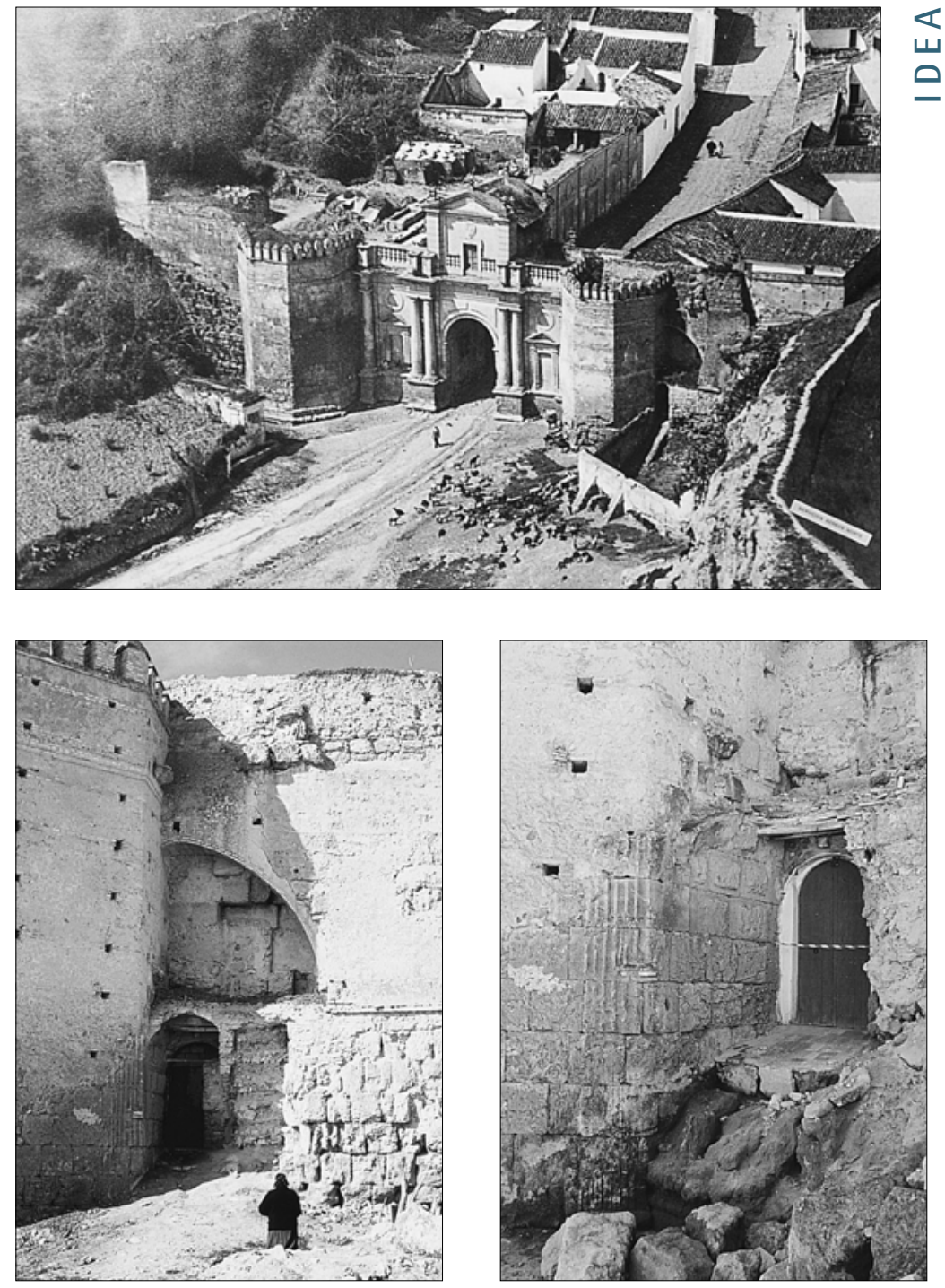

humedades de infiltración a las fábricas, con un desarrollo vertical mayor en el lienzo sur (sobre los $7 \mathrm{~m}$. respecto de la cota de suelo exterior actual) que en el norte (sobre los $2 \mathrm{~m}$.). Al efecto disgregador del agua especialmente sobre los paramentos de calcarenita más antiguos se suman los de las humedades de capilaridad debidas a las filtraciones y escorrentías del subsuelo y al efecto de las salpicaduras del agua de lluvia sobre las partes bajas de los paramentos. La acción directa del agua de lluvia es también especialmente grave por la pérdida total de función impermeabilizadora de los pavimentos de cubierta y de los remates de elementos singulares.

El deterioro generalizado de los revestimientos de la fábrica de ladrillo de la puerta neoclásica, la aparición masiva de plantas superiores, la oxidación de vástagos y refuerzos metálicos, han acelerado la extensión y la gravedad de las patologías: pérdida de elementos decorativos y molduraciones, caída de fragmentos de las cornisas, etc.

En el contacto de la bóveda con el arco de la portada oriental se encuentra una grieta que recorre buena parte de su desarrollo y que se prolonga hasta el late-
Foto 4. Fotografía aérea de la Puerta de Córdoba h. 1966 (Servicios Aéreos Norte). Se puede apreciar que en esta fecha aun se conserva la parte inferior del lienzo norte junto a la poterna, utilizada como salida al corral de bestias a través de una rampa.

Foto 5. La poterna y el lienzo norte en 1982 (F. Amores).

Foto 6. Estado actual de la poterna. 

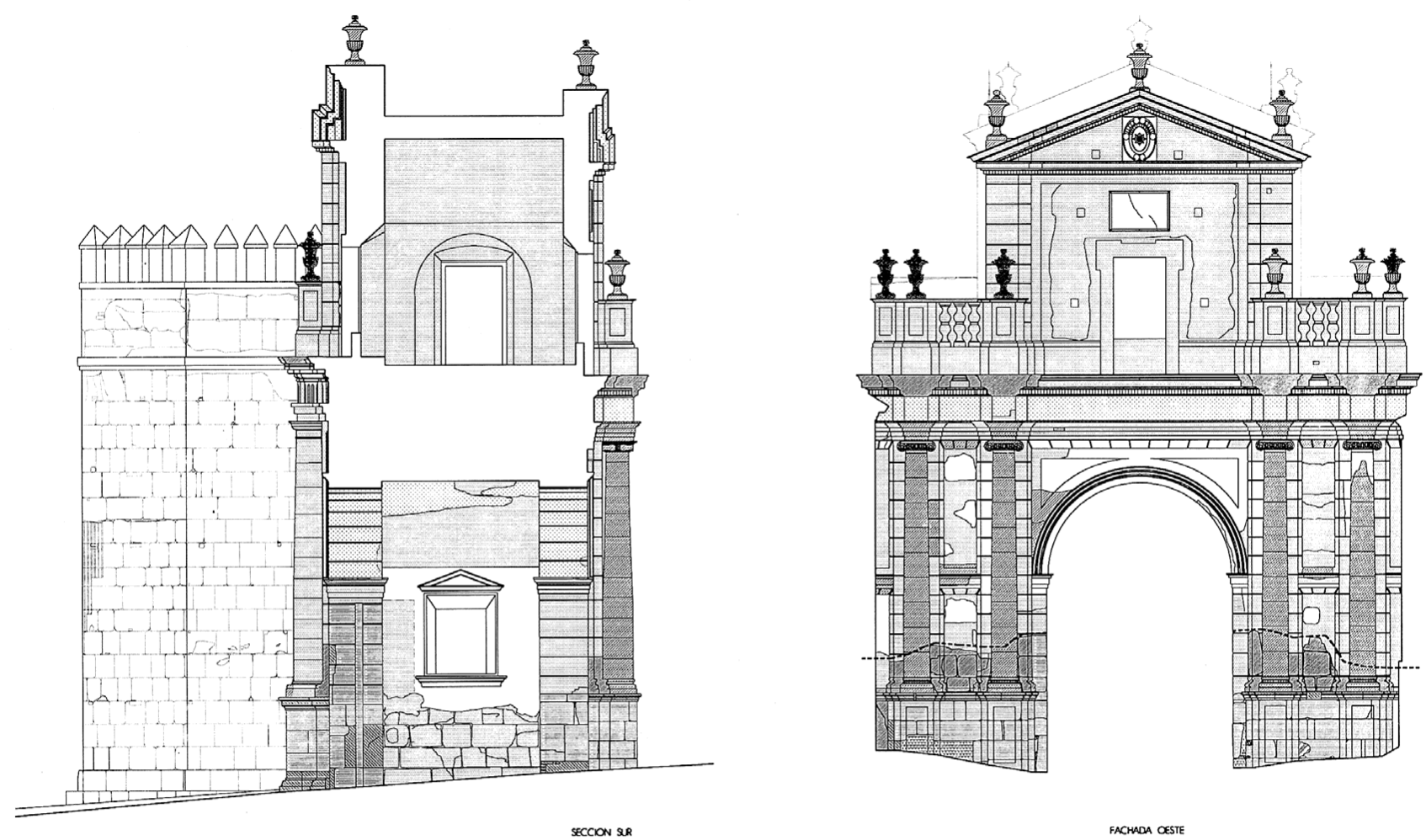

SECCION SA

\begin{tabular}{|c|c|c|c|}
\hline A MOOFCACIONES SPeEFFCWES & & a peodion of Mutean fetreo & \\
\hline A. ATEuciones Cromiticas & 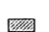 & a1. CON FOancion of HeCOS & 罱 \\
\hline 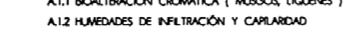 & $E$ & 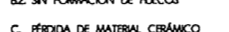 & 圆 \\
\hline AI3 PATAOAS & 四 & 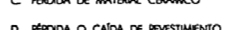 & $\square$ \\
\hline 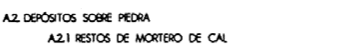 & $\square$ & 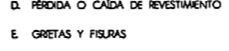 & $\square$ \\
\hline N22 MORTEROS DE CENENTO & 莱 & 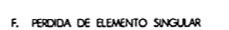 & 急 \\
\hline
\end{tabular}

ral norte del vano central, afectando al muro de fábrica mixta. Esta grieta puede tener su origen en un antiguo asiento diferencial con motivo del recrecido del ático o acciones de origen sísmico. De cualquier forma, como ya hemos dicho, parece más probable que estas deformaciones se deban a una pobre trabazón de las partes y a las vibraciones que transmite el paso de vehículos por el vano. Estas grietas pueden estar más o menos estabilizadas teniendo en cuenta que la cimentación descansa directamente sobre un terreno de transición a margas de gran capacidad resistente.

Los daños más generalizados son superficiales, pérdidas puntuales de material debido a las acciones térmicas, erosión del viento (corrasión), acción del agua en todos sus estados -especialmente por heladicidad e infiltración- y la vegetación que crece sobre los paramentos y en los elementos singulares. En la fábrica de ladrillo se aprecia pérdida de parte de algunos ladrillos y del mortero de las juntas, fundamentalmente en elementos decorativos, molduras y cornisas.

El estado de la piedra es distinto según su función estructural u ornamental, su orientación y su altura. El diagnóstico de su estado actual de conservación está basado tanto en el trabajo de laboratorio, mediante ensayos con muestras extraídas del monumento, como en el estudio de los indicadores visuales de alteración en un exhaustivo trabajo de campo. De manera que se ha realizado el grafiado de las zonas según su alteración más relevante y se han señalado otras patologías buscando, en cualquier caso, no hacer demasiado compleja la lectura de los planos, cuyo fin último es su utilización en la obra (fig. 6).

Las cubiertas tienen problemas de filtraciones y pérdidas de juntas que afectan de humedad a las bóvedas y macizos inferiores. El problema más grave es la permeabilidad de los adarves, tanto sobre las torres como sobre los laterales del vano central, donde se acumula la suciedad, el desarrollo de plantas es intenso y el precario sistema de evacuación de las aguas a través de mechinales no cumple su labor.

\section{VALORACIÓN Y PROPUESTA DE INTERVENCIÓN}

El estado actual de la Puerta de Córdoba de Carmona es el resultado de gran diversidad de factores y agentes que han interactuado a lo largo del tiempo. 
Pueden resumirse en dos: por un lado, la acción del medio natural -básicamente la climatología y la acción biológica-y, por otro, la acción antropogénica, en forma de leves agresiones puntuales $y$, sobre todo, en las últimas décadas, debido a la falta de un mantenimiento adecuado. De los análisis efectuados se deduce que es evidente la necesidad de restablecer las cualidades del monumento y protegerlo de los factores de degradación que han modificado su aspecto anterior.

Como se ha apuntado más arriba, el proyecto en esta primera fase propone una intervención de pura conservación. La metodología general aplicada supone una actividad multidisciplinar para la intervención mediante la colaboración de arquitectos, arqueólogos, historiadores, restauradores, químicos y operarios especializados.

Para garantizar la conservación y transmisión de sus valores irrepetibles, se hace necesario considerar la posibilidad de introducir contenidos funcionales que colaboren a su preservación. La puesta en uso del ático puede ser un elemento decisivo para favorecer el mantenimiento, si bien será objeto de la siguiente fase de intervención.

El proyecto de intervención sobre los aspectos funcionales, tan directamente relacionados con el futuro de la Puerta de Córdoba, ha consistido en potenciar unos y eliminar otros:

Acceso: siendo ésta la función principal no se considera deseable la eliminación del tráfico de vehículos, pero sí la reducción sustancial de su volumen e incluso la prohibición de paso de vehículos de gran tamaño como autobuses turísticos. Se han introducido en el proyecto un conjunto de actuaciones destinadas a aminorar el efecto del paso de vehículos: zunchado de las bóvedas, resanado de grietas y fisuras, cosido de las mismas y mejora de la calidad y plasticidad de los morteros de revestimiento.

Soporte: esta función estática de la Puerta se conserva intacta en la I a fase. Todos los elementos "muebles" añadidos a sus paramentos -las lápidas con inscripciones y el nicho del cuadro de la Virgen de Gracia, este último objeto de una restauración futura por parte del I.A.P.H.- se consideran parte de la misma. Precisamente esta razón refuerza los argumentos para justificar la intervención como de "mera conservación".

Depósito: traslado del material almacenado de la puerta sobrante tras la intervención a un depósito municipal.

Aprovechando los restos de revocos existentes, se extraerán muestras para analizar y restituir los colores de las fachadas neoclásicas, para lo cual se prevé un estudio más detallado de enlucidos y coloraciones, facilitado por la presencia permanente de los andamios durante la obra (si fuera posible, el IAPH acometería un estudio colorimétrico con la tecnología adecuada). Este aspecto es especialmente valorado en este proyecto, coherente con el carácter general de la intervención, que hemos calificado como de "simple conservación", lo que nos obliga a considerar que la imagen-color de la Puerta de Córdoba debe ser "re-conocida" tras la restauración para el mantenimiento de sus valores de identidad en la memoria colectiva (fig. 7).

Las intervenciones más significativas de la $I^{\text {a }}$ fase incluyen también un conjunto de medidas preventivas que palien el efecto de los factores naturales (se han excluido del ámbito de esta primera fase los espacios interiores: pasajes laterales y hueco de escalera original en los que se intervendría en la segunda fase).

Drenajes: trabajos destinados a reducir el efecto de las humedades de infiltración procedentes de relleno y el alcor del trasdós de los lienzos y torres que flanquean la puerta. Se han tanteado diversas soluciones para su eliminación, optándose finalmente y por lo que afecta a esta primera fase de obra, por soluciones ya contrastadas y en cierto modo tradicionales como las que suponen la creación de barreras al agua de infiltración procedente del terreno mediante drenajes más o menos profundos según las posibilidades de excavación en el perímetro del monumento. La profundidad deseable puede exigir la disposición de entibaciones y la realización de las zanjas por bataches.

Piedra: limpieza y tratamientos de consolidación e hidrofugación con los productos seleccionados en labo-

Foto 7. Fachada este

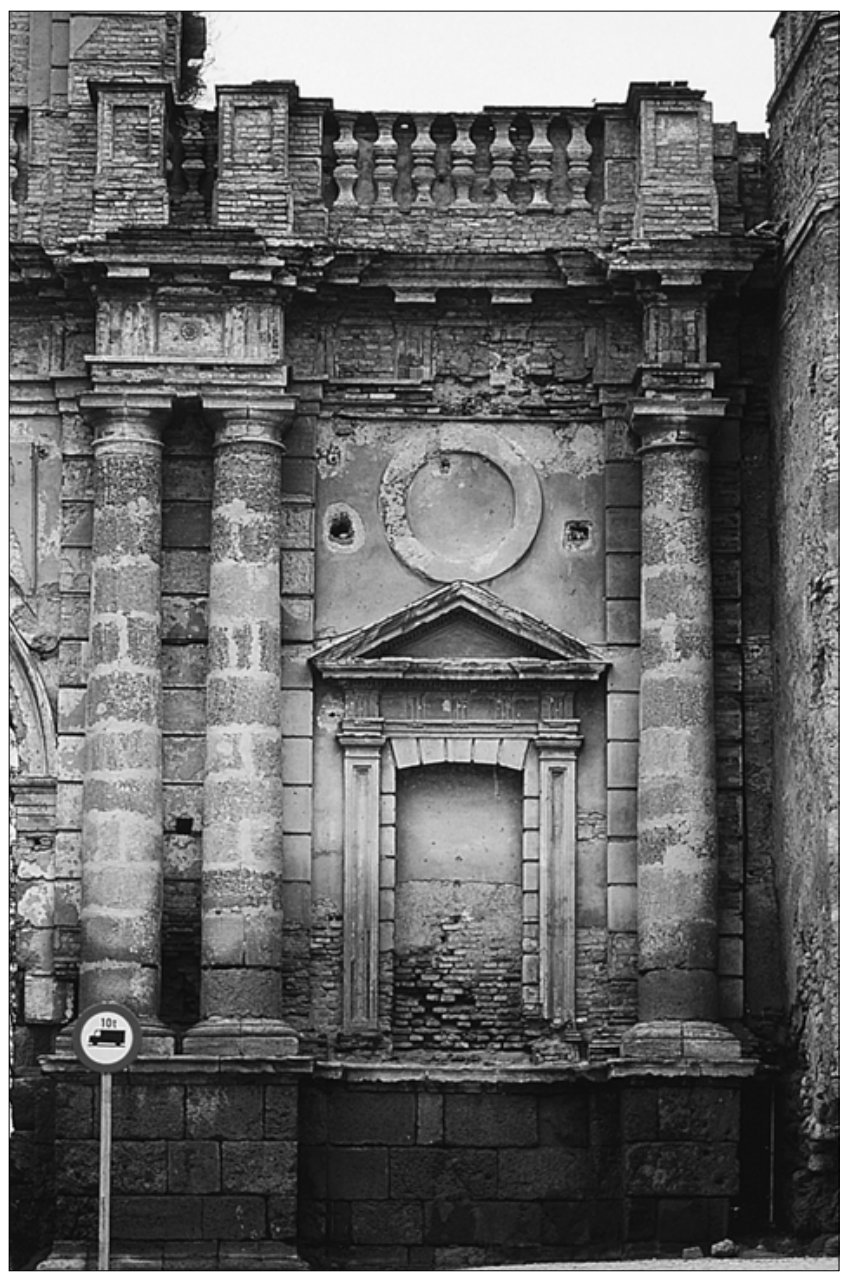




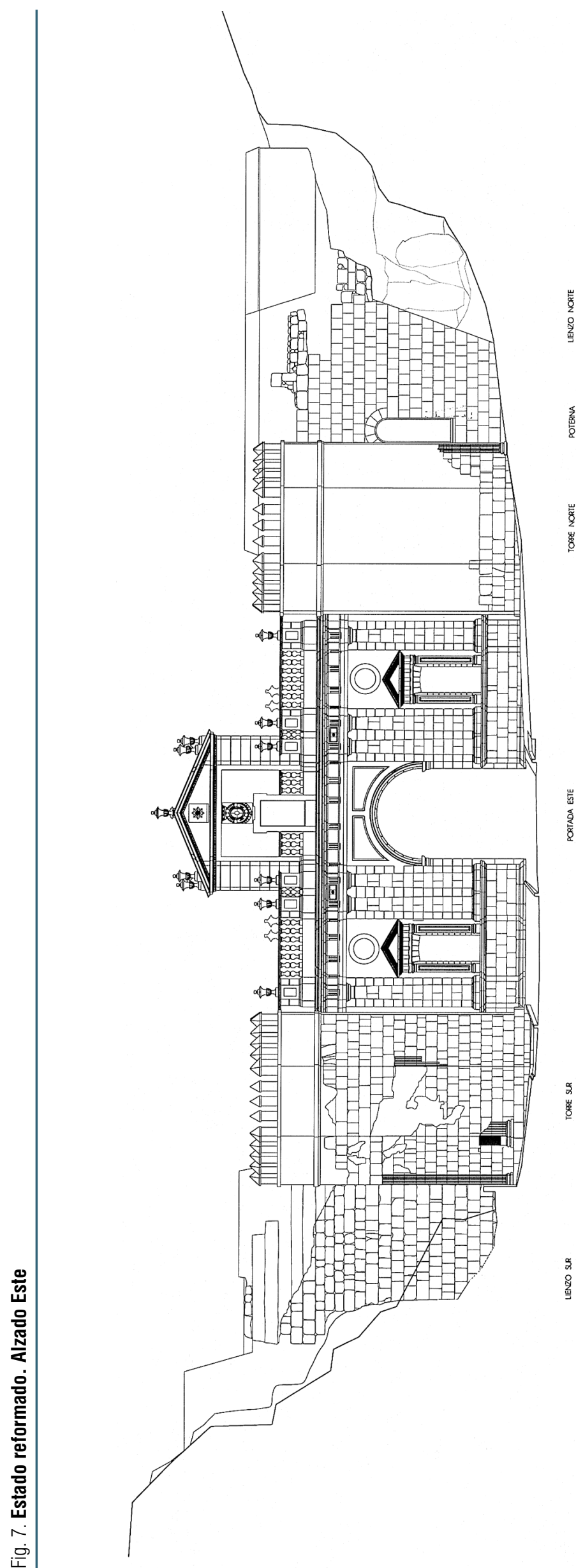

ratorio. Tratamiento de fisuras y restitución de material a base de morteros especiales.

Revestimientos, cornisas y elementos decorativos: anclajes y vástagos de acero inoxidable. Nuevos revocos de cal. Consistirán estos trabajos en la eliminación de vegetación, musgos, líquenes y algas, saneado y rejuntado de llagas y juntas con mortero de cal similar al antiguo (aunque mejorado con un 10\% en volumen de cemento blanco) con dosificación 1:1:7 en los paramentos de ladrillo. Los paramentos neoclásicos se revestirán mediante revoco de cal coloreado con pigmentos naturales, consolidándose las lagunas de mortero antiguo existentes.

Cubiertas: eliminación de plantas superiores, impermeabilización y nuevo sistema de evacuación de aguas pluviales y protección de las cornisas de los cuerpos altos frente a humedades de infiltración.

Consolidación estructural: Las operaciones principales están destinadas a la consolidación del lienzo norte mediante la recuperación de la cortina de piedra exterior (fig. 8) así como al atirantado y zunchado del cuerpo alto. Otras consolidaciones menores consisten en el cosido de las rupturas observadas en los muros de piedra y ladrillo, en la bóveda del vano central y en los elementos ornamentales de las fachadas, mediante llaves de acero inoxidable e inyección de resina epoxi y sellado de grietas y fisuras. Para la ejecución de la obra será importante la localización de una cantera en uso de donde extraer la piedra alcoriza de naturaleza similar a la existente en el monumento que pueda utilizarse en las reposiciones precisas y en el nuevo paramento de sillares del lienzo norte.

Instalación eléctrica: nueva red eléctrica trazada de forma menos visible (deben desaparecer los cables de fachada) y más segura que la actual. Puntos de luz y tomas de corriente racionalmente distribuidos y ubicados según las necesidades inmediatas de uso y de mantenimiento.

Carpintería y cerrajería: disposición de nuevas carpinterías de madera en los vanos del ático y de la poterna y protección del cuadro de la Virgen de Gracia que restaurará el I.A.P.H. (fig. 9).

\section{SEGUIMIENTO ARQUEOLÓGICO DE LA OBRA}

La obra va a suponer una oportunidad extraordinaria de profundizar en el conocimiento de la Puerta de Córdoba y elaborar una hipótesis contrastada de su estado original bien ajustada a los vestigios materiales y el análisis historiográfico. Partes importantes del monumento y su entorno han quedado sin investigar en la primera campaña de excavaciones, por ello las actividades de carácter arqueológico se centrarán en los siguientes aspectos:

- Área de la poterna, tanto exterior como interiormente. La excavación con metodología arqueología de esta zona a raíz de los drenajes a introducir y del 


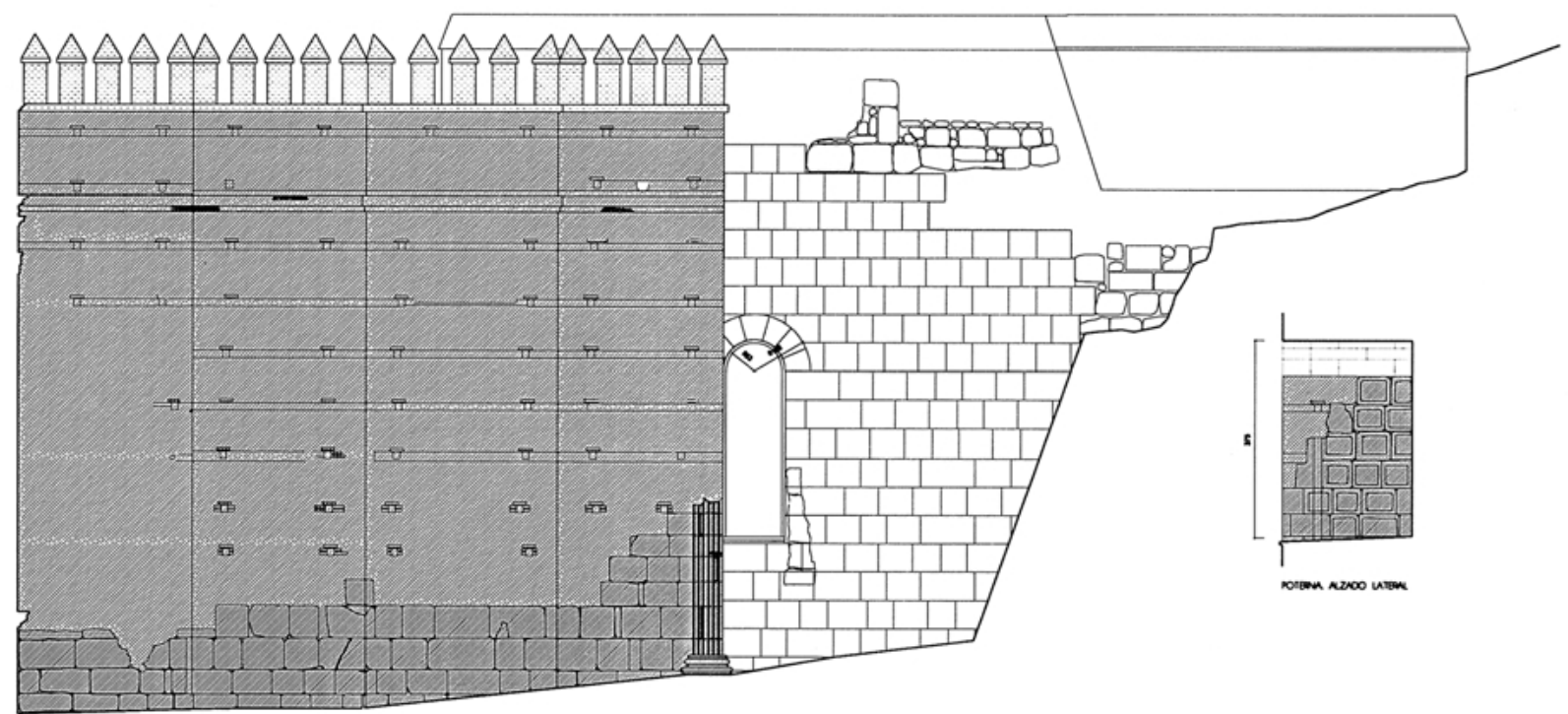

recrecido del lienzo norte desde cimentación va a permitir conocer detalles relevantes de la "singularidad" que la poterna introduce en la simetría general de la puerta como elemento defensivo. Consideramos esta excavación imprescindible para dilucidar el aspecto interior del torreón norte y su conexión con la muralla.

- Interior del lienzo sur. También con motivo de la disposición del drenaje tendremos ocasión de conocer los restos de la puerta en el lado en que se asienta la casa de los años 70. Esta excavación permitirá documentar la hipótesis arqueológica de la existencia de una cámara posterior asociada al torreón sur.

- Registros, con metodología arqueológica, de paramentos (lienzos de muralla y lateral sur-bóveda del vano central), enlucidos y puntos singulares no analizados en la primera campaña, como son: el trasdós de la bóveda del vano central, para determinar sus características constructivas y fechar su ejecución; el macizo norte de la puerta, donde debió existir una escalera de disposición simétrica a la que ocupó el lado sur que si está documentada; por último, la azotea norte para la documentación, mediante una cata, de esta posible escalera de acceso a los cuerpos altos de la puerta romana original.

- Documentar la posible cimentación de las pilastras del vano central de la Puerta que aparecen representados en los dibujos de 1774 y 1775, rematados por pirámide y esfera.

- Otros estudios puntuales del entorno inmediato, que incluyen algunas excavaciones puntuales y el análisis del pozo existente en el extremo occidental de la casa sur.

El sentido de estas actuaciones no está tanto en el apoyo a la obra de esta I ${ }^{\text {a }}$. fase, como en la documentación de aspectos que consideramos fundamentales para la

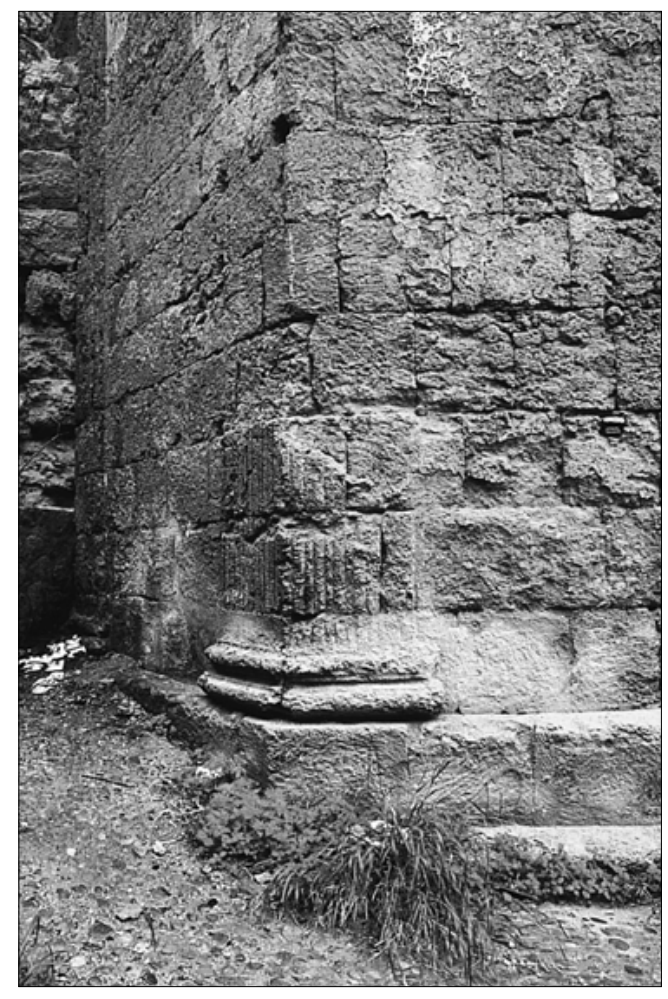

Foto 8. Pilastra de la torre sur y restos de revestimientos sobre el aparejo romano segunda fase de puesta en valor y presentación del monumento. El faseado de la obra adquiere, por tanto, un argumento más: con una intervención global no sería posible acometer con garantías el conocimiento exhaustivo de las estructuras conservadas y el análisis históricoarqueológico del B.I.C. y su entorno, (fig. I0).

Por último, cabe insistir en la necesidad de que las intervenciones que sobre nuestro patrimonio histórico se realicen sin olvidar la importancia de desarrollar los estudios previos al proyecto, bien implementados mediante equipos interdisciplinares, en un proceso que incorpora las ciencias aplicadas. En este proceso, el $\varangle$ ए 
$\longleftarrow$
$\square$
$\square$

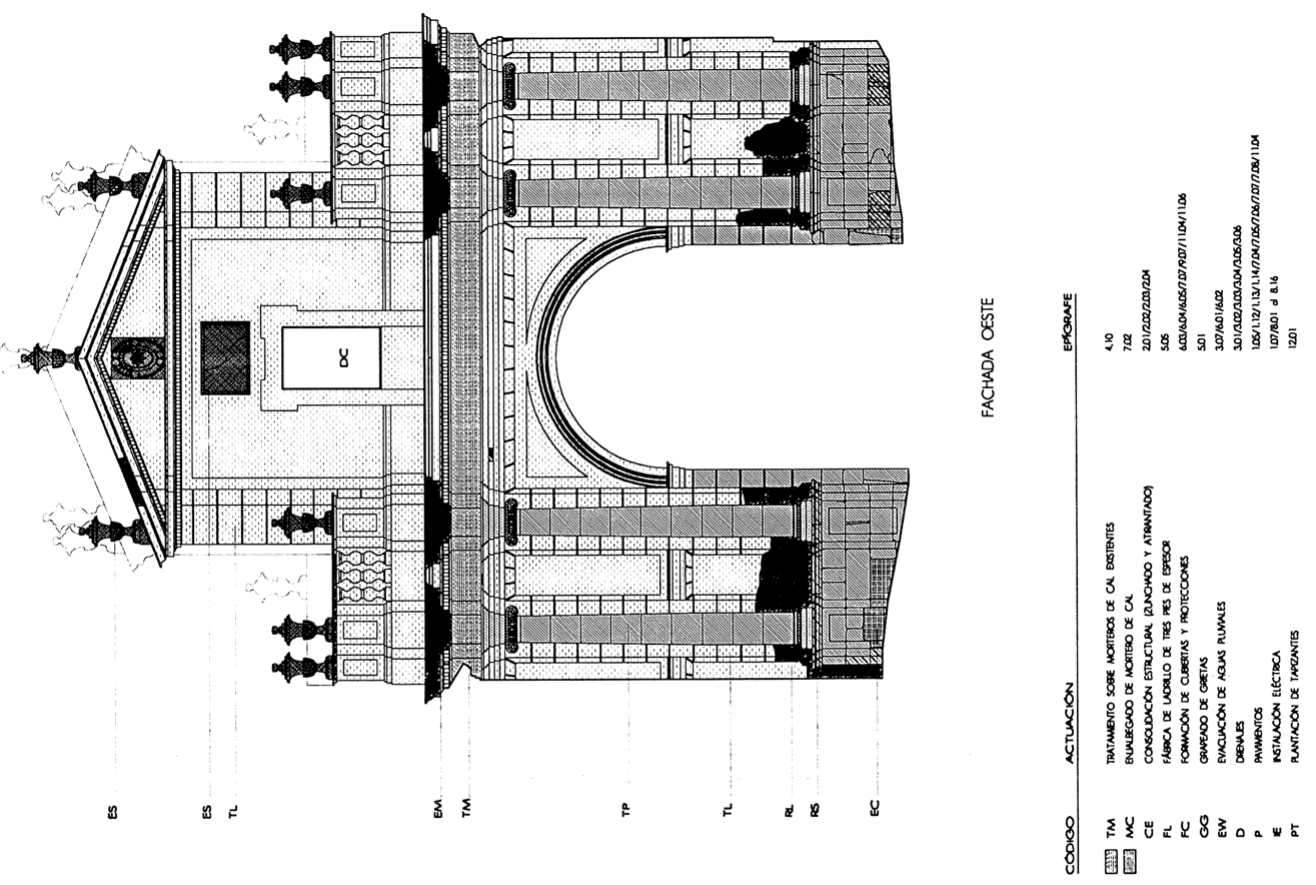

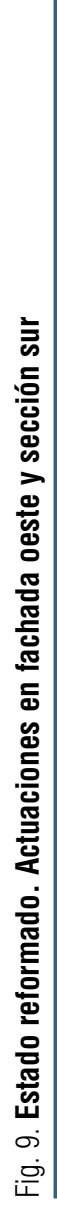
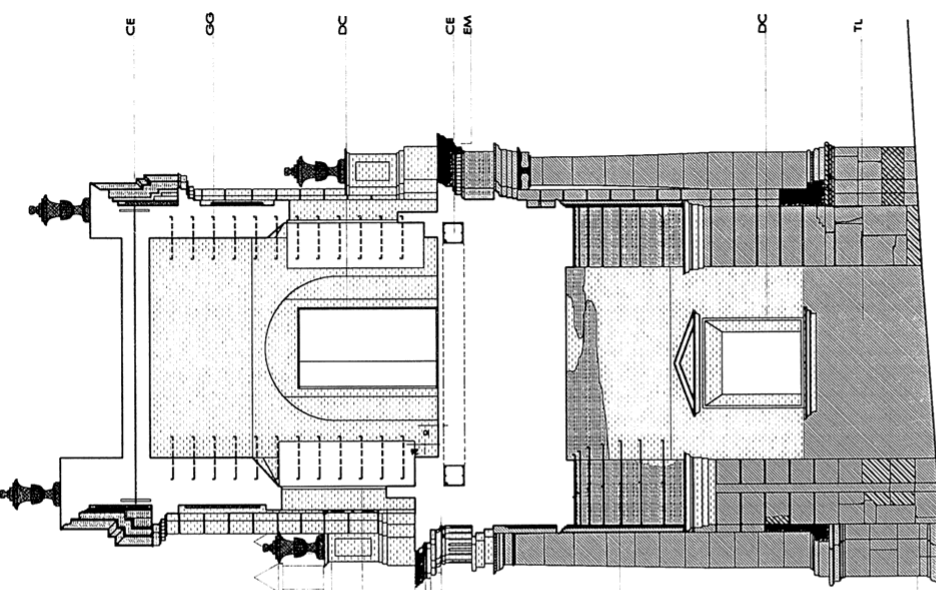

8

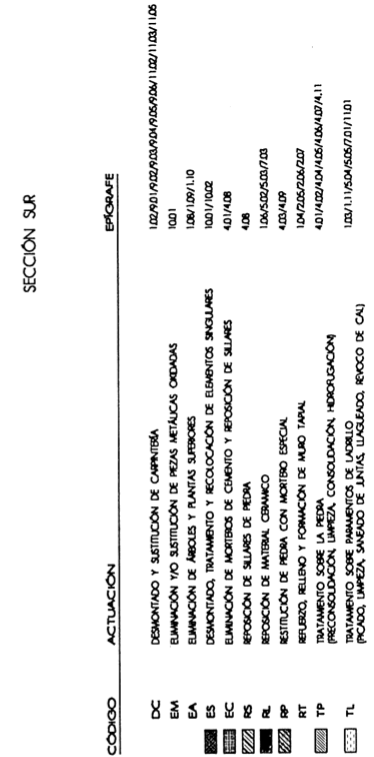


proyecto es el instrumento fundamental, aunque no definitivo, de la conservación patrimonial que pasa por su ejecución efectiva en obra con la participación de empresas cualificadas. De este proceso interdisciplinar, tantas veces invocado y teorizado en publicaciones es- pecializadas en patrimonio histórico, queremos destacaar que la intervención en la Puerta de Córdoba de Carmona puede servir paara constatar la viabilidad y las posibilidades de aplicación material de esta metodología en nuestro contexto cultiral y social.

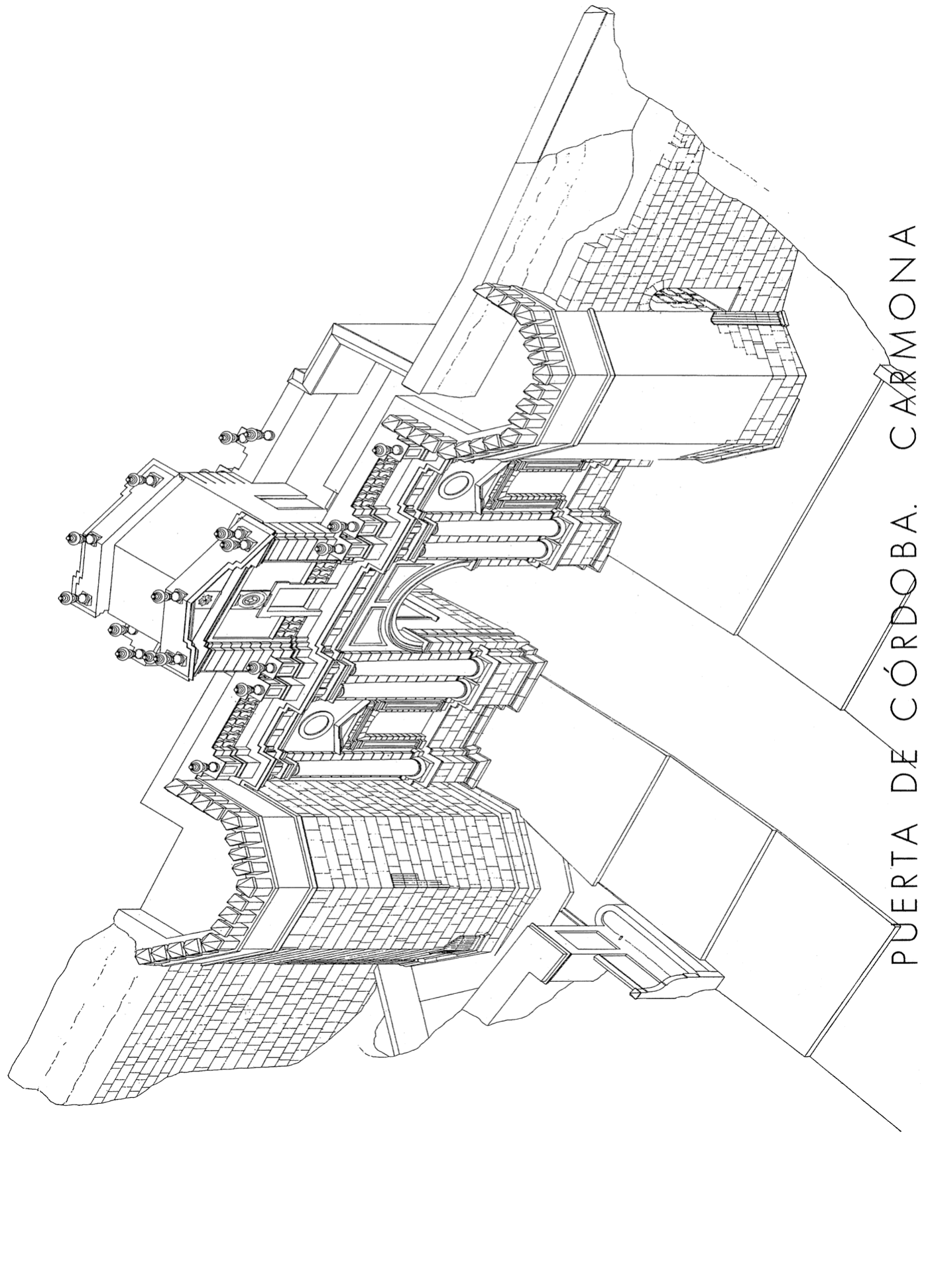




\section{Ficha técnica del proyecto} de restauración $I^{2}$ Fase

Propiedad

Ayuntamiento de Carmona

Realización:

Instituto Andaluz del Patrimonio Histórico. Dirección General de Bienes Culturales. Consejería de

Cultura. Junta de Andalucía. 1995-1997.

Dirección-Coordinación: Román Fernández-Baca Casares, arquitecto.

Lorenzo Pérez del Campo historiador del arte.

Investigación histórica: Historia documental y prelevantamiento: Alfonso Jiménez Martín; Arqueología: Reyes Ojeda Calvo, Miguel Ángel Tabales Rodríguez; Estudio tafonómico y paleobiología: Eloísa Bernáldez Sánchez

Caracterización de materiales y evaluación de tratamientos:

Rosario Villegas, Jesús Espinosa, Esther Ontiveros, Francisco Gutiérrez y Lourdes Martín.

Estudio geotécnico: AICIA e Instituto Universitario de las Ciencias de la ConstrucciónEscuela Técnica Superior de Arquitectura José Luis de Justo Alpañés.

Intervención arquitectónica: Arquitecto: Antonio Tejedor Cabrera. Arquitectos colaboradores: Mercedes Linares Gómez del Pulgar, Pedro Lobato Vida, Daniel Plaza Gómez, María losé Llanos Rodríguez; Arquitecto técnico: Ángel González Martín

Apoyo taquimétrico: Carlos

Encina Lobo. Maqueta: Jacinto Gómez.

Presupuesto general obra: 48.500 .000 ptas.

\section{Notas}

1. Ambas puertas -la de Córdoba y la de Sevilla- se situaban en los extremos del Cardo máximo cuyo trazado se conserva hoy día en las calles Dolores Quintanilla, Sta. María de Gracia, Martín López y Prim

2. Para una evolución de la trama urbana en relación con las puertas de la ciudad, cfr. IIMÉNEZ MARTÍN, A. La Puerta de Sevilla en Carmona. Consejería de Obras Públicas y Transportes. Junta de Andalucía. Málaga, 1989, p.264 a 267 (la fig. I procede de la página 26 I de este libro). Además, se puede consultar la siguiente bibliografía:

- COLLANTES DE TERÁN, F.; HERNÁNDEZ DÍAZ, J:; SANCHO CORBACHO, A.: Catálogo Arqueológico y Artístico de la Provincia de Sevilla. Tomo II. Sevilla, 1943.

- MORALES, A. et alli. Guía Artística de Sevilla y su provincia. Diputación Provincial de Sevilla. Vitoria, 1989.

- Historia del Arte en Andalucía. Tomo I. Ed. Gever,

- MARTA, R. Técnica Constructiva Romana. Edizioni Kappa. Roma, 1986.

3. La Puerta de Córdoba de Carmona está declarada Bien de Interés Cultural (B.I.C.) con categoría de Monumento Histórico-Artístico por Decreto de fecha 3 de junio de 193 según recoge la ficha-diagnóstico n SE/025/005 del Plan General de Bienes Culturales. Por lo que respecta al planeamiento vigente, está catalogada con el grado A, protección integral, por las Normas Subsidiarias de Carmona.

4. Las posibilidades de desarrollo de estas intenciones están siendo estudiadas en coordinación con el I.A.P.H. y pasan por la decidida colaboración del Excmo. Ayuntamiento de Carmona para encontrar las fórmulas adecuadas (cesión, adquisición, etc.) de incorporación al proyecto de los espacios asociados a los vanos laterales de la Puerta que en la actualidad están anexionados a las casas contiguas.

5. Cfr. MARTíN, A. Ensayos y experiencias de alteración en la conservación de obras de piedra de interés histórico artístico. Fundación Ramón Areces. Madrid, 1990. pp. 126 a 238.

6. El aparejo romano de la piedra en lienzos y torres es de sillares isodómicos a soga y tizón de dimensiones próximas al pie itálico: 53 × 106 cms.

7. HERNÁNDEZ DÍAZ et alli. Catálogo Arqueológico y Artístico de la Provincia de Sevilla. Tomo II. Sevilla, 1943, figs. 443 y 444

8. Las dimensiones básicas de la Puerta de Córdoba son:

- Diferencia de cota entre el eje de la calle $(+217)$ y el Cortinal Gil de Palma (+235): 18 m.

- Alzado a la Vega, con lienzos laterales incluidos: $60 \mathrm{~m}$.

- Alzado sin lienzos laterales: $35 \mathrm{~m}$

- Fachada entre torreones: $19 \mathrm{~m}$

- Altura total de la fachada Este: 17 m.

- Profundidad del vano central: 6 m. Anchura del vano: 4,40 m. Altura del vano: 7,10 m.

- Sección de los vanos laterales hoy clausurados: I,40 × 3,90 m.

- Altura de los torreones: $13 \mathrm{~m}$.

- Fachada interior: anchura de 12,50 m. altura de 15,80 m.

9. El color general de los revestimientos de la puerta es un amarillo "calamocha" próximo al color de la piedra alcoriza. Restos de enlucido blanco y color almagra se observan en molduras y elementos decorativos de las fachadas neoclásicas. También existen restos de enlucidos con sillares esgrafiados en el torreón sur.

10. La lápida del frontón es el escudo de la ciudad con su lema: SICUT LUCIFER LUCEI IN AURORA ITA IN VANDALO CARMONA. En la otra se lee: "TMP CONSVMIT GOTHVS DINVIT PETRVS REEDIFICAT ENRICVS PVNIVIT" texto que continúa en dos líneas más de difícil transcripción.

I I. En 1989 la Delegación Provincial de Cultura realizó de oficio una campaña de obras de emergencia cuyas tareas consistieron en:

- Limpieza de vegetación parásita.

- Desmontado de elementos de cornisa sueltos y en peligro de caída sobre la vía pública.

- Fijación de elementos sueltos sin peligro de caída inminente.

- Almacenamiento, previa clasificación de los elementos desmontados, para su posterior colocación.

La obra fue realizada por la empresa constructora Joaquín Pérez S.A. con la dirección técnica de D. Juan Antonio Fernández Naranjo, arquitecto y D. Juan Luis Barón Cano, arquitecto técnico.

12. Sobre la intervención arqueológica, cfr. OJEDA CALVO, R. y TABALES RODRÍGUEZ, M. A.: "La investigación arqueológica en Bienes inmuebles. Metodología aplicada en la Puerta de Córdoba de Carmona". En Boletín del Instituto Andaluz del patrimonio Histórico, n.15, pp.4I a 52

13. Ibidem, n. I 3, p.52.

14. Para el contenido de este estudio, cfr: BERNÁLDEZ, Eloísa: "El nicho ecológico de la paleobiología en el Patrimonio Histórico". En Boletín del Instituto Andaluz del Patrimonio Histórico. N.16. pp. 48 a 59

15. Los planos incluidos en el "Informe-Memoria de la excavación arqueológica" aportaron valisosos detalles sobre la composición material de los paramentos si bien al ser revisados se comprobó que no estaban completos y no tomaban en consideración los puntos taquimétricos obtenidos expresamente para el levantamiento.

16. Las características de los tratamientos son:

$\begin{array}{lllll}\text { Producto: } & \text { Tegosivin HLI00 } & \text { ARD } 55.050 & \text { Tegovakon V } & \text { Consolidante } \mathrm{OH} \\ \text { Composición: } & \text { Compuesto } & \text { Resina } & \text { Silicato de } & \text { Silicato de } \\ & \text { organosilícico } & \text { acrilililicónica } & \text { etilo } & \text { etilo } \\ \text { Materia activa: } & 100 \% & 10 \% & 75 \% \text { peso } & 75 \% \text { peso } \\ & \text { (para diluir al } 5 \%) & & & \end{array}$

17. Las canteras estudiadas se han escogido siguiendo criterios arqueológicos. Son las siguientes:

I. Cantera de la Necrópolis de Carmona

II. Pequeñas canteras romanas de los alrededores de Carmona en la zona NE.

III. La Batida. Explotaciones modernas, que es posible ya se utilizaran en época romana.

IV. Castillo de Mairena del Alcor.

V. Puerto del Judío. Se trata de la más importante explotación romana localizada en esta zona.

18. Se contempla en el proyecto un plan de control (ensayos y análisis) para verificar la eficacia de los tratamientos. 